Indeed, the resources required to conduct an HIA and the likely outcomes need to be weighed by managers prior to embarking upon an HIA. An important part of the screening process should be consideration of the balance between the resources required to undertake the HIA and the likelihood of influencing outcomes and affecting significant health gain. Indeed, the resource issue is critical to the viability of integrating HIA into core health service activities.

The HIA did, however, provide a useful framework for strengthening the collaborative relationship between the Council and the Division of Population Health. It improved both organisations' understanding of each other's business, the broader definition of health and, specifically, the inter-relationship between the environment and physical activity and social cohesion. The process also helped to up-skill staff and facilitated the sharing of information and resources. Successful completion of the project also led to ongoing local developments, including a current HIA using a different methodology with a different local council. This current HIA is being conducted on a capital works program with similar environmental features and aims to assess and compare HIA methodologies (desk-based versus intermediate) with a view to evaluating the feasibility of methods and providing recommendations on when to apply particular approaches.

\section{REFERENCES}

1. Neville L, Furber S, Thackway S. et al. A health impact assessment of an environmental management plan: The impacts on physical activity and social cohesion. Health Promotion Journal of Australia. (Accepted for publication, 2005.)

2. Neville L, Furber S, Thackway S, Wallin T, Gray E, Mayne D et al. Health impact assessment on the Shellharbour Foreshore Management Plan, Illawarra Area Health Service and Shellharbour Council, 2004. Available at http://chetre.med. unsw.edu.au/files/IAHS_Final_HIA_Report.pdf .

\title{
HEALTH IMPACT ASSESSMENT ON AN INTEGRATED CHRONIC DISEASE PREVENTION CAMPAIGN
}

\author{
Blythe O'Hara, Jenny Hughes and Paul Kehoe \\ Centre for Chronic Disease Prevention and \\ Health Advancement \\ NSW Department of Health \\ Hannah Baird \\ National Prescribing Service Ltd \\ Therese Milham \\ Health Services Policy Branch \\ NSW Department of Health
}

\section{Sharon Hills}

Access Solutions

A priority in the NSW Chronic Disease Prevention Strategy 2003-2007 is to: Design, test, develop and evaluate a state-based pilot of an overarching 'integration' strategy to draw together existing programs and activities dealing with tobacco, alcohol, nutrition, physical activity and mental health promotion with a view to progressing state-wide implementation if the evaluation results are favourable.

It is proposed that this priority be addressed through a chronic disease prevention campaign promoting changes in knowledge, attitudes and practices on contributory risk factors to decrease the prevalence of chronic disease among 35-55 year olds. For the purposes of this campaign, chronic diseases include cardiovascular diseases, cancers, chronic lung diseases and type 2 diabetes.

The proposed campaign underwent a health impact assessment (HIA) between February and October 2004 by the Health Promotion Strategies and Settings Branch in the NSW Department of Health's Centre for Chronic Disease Prevention and Health Advancement.

\section{WHAT WAS DONE}

The HIA of the proposed chronic disease prevention campaign was undertaken using the procedures described by Scott-Samuel et al: screening, scoping, assessment, negotiation and decision making, and evaluation. ${ }^{2}$

\section{WHAT WAS FOUND}

Screening identified that the proposed campaign was suitable for an HIA: it was in an early stage of development and so able to be influenced by recommendations; it had a well-defined program structure of aims, goals, and targets; and there were indications from available evidence that the proposed strategies of social marketing and complementary initiatives would have a positive effect in reducing the risk of chronic disease.

As part of the scoping phase an existing, informal steering group for the HIA was formally appointed as such. It included representation from the Centre for Chronic Disease Prevention and Health Advancement, the Centre for Aboriginal Health, and Population Health from the then Wentworth Area Health Service. Key questions identified for the HIA were (i) Are lifestyle risk factor campaigns effective at changing behaviours? and (ii) Are population subgroups differently affected by lifestyle campaigns? Data type and sources to answer these questions were identified, and included NSW population health data, literature reviews, and the opinion of key informants.

Assessment of the sources of data determined that the NSW population is at risk of chronic disease arising from the identified risk factors; that health status and 
prevalence of chronic disease risk factors are associated with disadvantage; and that chronic disease risk factors are interactive and synergistic in effect. It was found that social marketing campaigns are more effective at promoting one-off rather than sustained behaviour changes; evidence is conflicting with regard to the effectiveness of integrated versus individual risk factor-focused campaigns; intersectoral partnerships improve campaign sustainability, duration and effect; and campaigns must address the socioeconomic issues specific to disadvantaged populations if those members of the community are to be reached. No potentially harmful effects of the campaign were identified.

Recommendations arising from the HIA included that the proposed campaign:

- deliver separate risk factor message streams under a coordinated program, thus combining individual and integrated approaches

- be tailored to subgroups in the population, and focus on low socio-economic status groups in its communication

- incorporate stress as a risk factor to be addressed

- focus on influencing the priming steps of behaviour change, rather than behaviour change itself

- establish partnerships with primary health care stakeholders

- use messages that are positive, confidence-building, simple and catchy

- ensure rigour in its evaluation to contribute to the evidence base.

\section{DID THE HIA MAKE A DIFFERENCE?}

The recommendations made by the HIA confirmed the key directions of the proposed campaign, in particular the feasibility and value of mounting an integrated response to chronic disease prevention. The recommendations also defined greater clarity for the proposed campaign's implementation foci, and increased its potential effectiveness to reach and influence disadvantaged populations.

All recommendations arising from the HIA were accepted by the Health Promotion Strategies and Settings Branch, and are planned for incorporation in the proposed campaign.

Funding approval for the proposed integrated chronic disease prevention campaign is pending, and remains a priority in the NSW Chronic Disease Prevention Strategy 2003-2007.

\section{REFERENCES}

1. NSW Health. NSW Chronic Disease Prevention Strategy 2003-2007, Sydney; NSW Department of Health, 2003: p 6.

2. Scott-Samuel A, Birley M, Ardern K. The Merseyside guidelines for health impact assessment. $2^{\text {nd }}$ edition. Liverpool: IMPACT, University of Liverpool, 2001. Available from www.ihia.org.uk/document/merseyguide3.pdf. 모ํ

\section{NSW PUBLIC HEALTH BULLETIN}

The NSW Public Health Bulletin is a publication of the NSW Department of Health. The editor is Dr Lynne Madden, Manager, Public Health Training and Development Branch. The Bulletin provides population health data and information to support public health action. The Bulletin is indexed by Medline and Index Medicus.

\section{Submission of articles}

A Bulletin article should be about 1500 words, not including tables and figures. News, comments and other reports should be 500-600 words. References should be set out in Vancouver style (see www. nlm.nih.gov/bsd/uniform_requirements.html). Send submitted manuscripts on paper and in electronic form, either on disc (preferably Word for Windows) or by email. The paper copy must be accompanied by a letter signed by all the authors. Full instructions for authors are available on request from the editorial office.

\section{Editorial correspondence}

Please address all correspondence and contributions to

The Editor, NSW Public Health Bulletin

Locked Mail Bag 961

North Sydney, NSW 2059

Australia.

Send email to phbulletin @ doh.health.nsw.gov.au. Telephone (61 2) 9424 5876, fax (61 2) 93919232.

\section{Distribution}

To obtain copies of the NSW Public Health Bulletin please contact your local public health unit or telephone (61 2) 9391 9942. A form for new subscribers or changes of address is printed in most issues of the Bulletin. There is also an online subscription form on the Bulletin's website. Copies of the current issue and all back issues can be downloaded in both PDF and HTML formats from www.health.nsw.gov.au/public-health/phb/phb.html. Back issues of the printed version are available from: Public Health Training and Development Branch NSW Department of Health

Locked Mail Bag 961

North Sydney, NSW 2059

Australia.

Copyright (C) 2005 NSW Department of Health

\section{NSW 2 OHEALTH}

